\title{
Swedish Match Company, Swedish snus and public health: a harm reduction experiment in progress?
}

The most powerful means to reduce the diseases caused by tobacco use are to prevent the initiation of use and to help users to achieve complete and lasting abstinence. For tobacco users who are unwilling or unable to completely give up their tobacco use, the possibility is increasingly being considered that such persons might be able to reduce their risk of disease and premature mortality by reducing their exposure to tobacco toxins. This conclusion may seem obvious, and various expert panels have repeatedly issued guidance based on these observations. ${ }^{1-5}$ Nonetheless, this public health strategy has been controversial because the purveyors of tobacco products have generally used the guidance as a tool to undermine public health efforts to prevent the initiation of tobacco use and facilitate cessation in those who use the products. ${ }^{26-9}$ Furthermore, even in cigarette smokers who have switched to cigarettes advertised as "low tar" or "light" the health benefits to those persons, if any have been small. ${ }^{2} 1011$

In the USA, smokeless tobacco products such as snuff and chewing tobacco might have been predicted to lessen overall tobacco attributable mortality to the extent that they provided an alternative source of tobacco delivered nicotine for persons who could not abstain from cigarette smoking. Unfortunately, smokeless tobacco products appear to have actually fuelled the public health problem caused by tobacco use by serving as entrées for youth to develop nicotine dependence and frequently to progress to cigarette smoking. ${ }^{12}{ }^{13}$ Youth smokeless tobacco consumption escalated greatly in the 1970 s and 1980 s, fuelled by development of what the industry termed "starter products", and aggressive marketing to youth following an industry described "graduation strategy" based on the nicotine delivery potential of the products. ${ }^{14}$ Smokeless tobacco marketing contributed to the initiation of tobacco use in a broader range youth than would have been expected to take up smoking and these tobacco users were then found to be more likely to initiate smoking than their peers. ${ }^{14}{ }^{15}$ Although the specific role of snuff is uncertain, it is plausible that smokeless tobacco marketing contributed to the escalation of smoking rates among youth and young adults in the 1990s. ${ }^{12} 13$

Part of the tobacco problem is that there are no meaningful standards by which to regulate tobacco product toxicity. ${ }^{2}$ Therefore, competition among tobacco companies is not necessarily based on actual reductions in toxicity of the products, nor has there been an apparent willingness of makers of the most deadly products to facilitate the transfer of their consumers to less deadly products because differing product types are often manufactured by competing companies (for example, cigarettes, smokeless tobacco, and cigars are typically marketed by different companies). Combined with the fact that treatment products are regulated in such a way as to make them generally less attractive and less available than tobacco products, ${ }^{516} 17$ it is not surprising that public health efforts to reduce the prevalence of tobacco use and the resultant harm have been extraordinarily difficult.

In Sweden, the tobacco marketing and regulatory situation has been different from that of most other countries in several respects, and Sweden has become one of the first developed nations to see a significant decline in tobacco attributable mortality. ${ }^{18} 19$ This decline has been associated with changing consumer preferences and regulatory policies that have contributed to a partial shift in nicotine intake from the most hazardous form (cigarettes) to less hazardous forms (snus form of smokeless tobacco and nicotine replacement medications). ${ }^{18}$ It is not clear to us how to apportion the contribution of the aforementioned specific factors in the reduction of overall tobacco attributable mortality risk. Nonetheless, we believe that the situation in Sweden might be considered a real world experiment in harm reduction that is in progress although we are concerned that not all of the signs are positive. What lessons for controlling tobacco attributable diseases might be drawn from the Swedish experience and might serve as guidance for public health efforts in Sweden as well as for other countries? The purpose of this commentary is to share some observations from the Swedish experience and discuss how they might provide guidance to tobacco disease control efforts.

Although it might be argued that the situation in Sweden is most relevant to other developed nations with an established consumer market for cigarettes, smokeless tobacco, and nicotine replacement, such as the USA and Norway, we believe that the Swedish experience offers some perspective as to potential issues and consequences of policies that would attempt to encourage harm reduction approaches in other countries as well. In offering this assessment, we distinguish the conceptual demonstration and importance of the Swedish experience (which we think is useful to consider) from the issue of whether or not smokeless tobacco should be generally promoted as a means of tobacco control (which we do not). 
Table 1 Percentage of daily cigarette smokers and snus users in Swedish adults

\begin{tabular}{llllll}
\hline & \multicolumn{2}{l}{ Cigarette smoking } & & \multicolumn{2}{l}{ Snus use } \\
\cline { 2 - 3 } \cline { 5 - 6 } Year & Males & Females & & Males & Females \\
\hline 1980 & 36.3 & 28.7 & & 16.6 & $<1$ \\
1985 & 29.9 & 27.3 & & 16.3 & $<1$ \\
1990 & 25.8 & 25.9 & & 16.3 & 1.3 \\
1993 & 23.3 & 23.4 & & 16.9 & 1.1 \\
1995 & 22.0 & 23.6 & & 17.2 & 1.2 \\
1996 & 21.4 & 23.3 & & 17.8 & 1.7 \\
1997 & 16.8 & 22.2 & & 18.9 & 1.7 \\
1998 & 17.1 & 22.3 & & 18.2 & 1.7 \\
\hline
\end{tabular}

Tobacco use trends in Sweden

In Sweden since 1980, cigarette smoking has declined in men, from $36.3 \%$ to $17.1 \%$, and in women from $28.7 \%$ to $22.3 \%$. Table 1 shows that these declining smoking rates have been associated with a small increase in snus use in men which has brought the prevalence of snus use to approximately equal that of smoking in men. The absolute and percentage reductions in smoking by women have been smaller than in men and snus use has remained below $2 \%$ in women.

Table 2 shows some differences in tobacco use trends by 15-16 year old youth as compared to adults since 1980 . In boys, rates of smoking and snus use have been relatively stable with the prevalence of snus use showing a tendency to exceed cigarette smoking slightly. In girls, following a drop in prevalence from $23 \%$ to $14 \%$ in 1985 , there has been little change in either smoking or snus use with smoking rates averaging about $4 \%$ higher than in boys and snus use never exceeding $1 \%$.

The reductions in smoking have been attributed to the promotion of snus in Sweden. ${ }^{18}$ However, there has also been a broad range of tobacco control efforts including increased communications about the dangers of smoking, increased restrictions on tobacco product marketing, increased taxation on tobacco products, and increased treatment availability, which complicate efforts to attribute changes in tobacco use primarily to single factors. The fact that snus has been less severely condemned than cigarettes may have contributed to the stability of its use in boys and the slight increase in men. However, the persistent very low use in girls and women suggest additional factors that may include social and cultural as well as male oriented marketing efforts. It cannot be concluded, from the data shown in the tables, the extent to which smoking reductions are attributable to the

Table 2 Percentage of daily cigarette smokers and snus users in Swedish adolescents (age 15-16 years)

\begin{tabular}{llllll}
\hline & \multicolumn{2}{l}{ Cigarette smoking } & & \multicolumn{2}{l}{ Snus use } \\
\cline { 2 - 3 } \cline { 5 - 6 } Year & Males & Females & & Males & Females \\
\hline 1980 & 12 & 23 & & NA & NA \\
1985 & 11 & 14 & & 13 & $<1$ \\
1990 & 13 & 19 & & 12 & $<1$ \\
1993 & 14 & 18 & 12 & $<1$ \\
1995 & 13 & 17 & 13 & $<1$ \\
1996 & 12 & 17 & 12 & $<1$ \\
1997 & 11 & 17 & 12 & $<1$ \\
1998 & 11 & 14 & 14 & $<1$
\end{tabular}

NA, not available. replacement of snus for cigarette smoking among tobacco users, and a better understanding of the potential extent and determinants of such a transfer will be important to determine.

Regulation, marketing, and consumer use of nicotine products

As has been described elsewhere, marketing and regulatory approaches generally favour tobacco products to such a degree that tobacco products are much more appealing and accessible than products proven to help people quit smoking. ${ }^{26}{ }^{617}{ }^{20}$ In the USA, this balance began to shift in 1996 when the US Food and Drug Administration issued restrictions on tobacco product marketing as part of its Tobacco Rule, ${ }^{21}$ and approved nicotine gum and two brands of nicotine patches for over the counter marketing ("general sales"). ${ }^{22}{ }^{23}$ However, the rejection of the FDA's Tobacco Rule by the US Supreme Court in 2000 may reverse some of the gains made since 1996 .

In Sweden the regulatory balance began to shift in the 1980s as authorities were quicker to allow non-prescription sales of nicotine gum than in most other countries. The trend has continued with a broad range of nicotine delivering medications including an oral inhaler, oral lozenge, nasal spray, transdermal patch, and oral tablet formulation being approved for sales without prescription since 1991. Approximately 3\% of nicotine consumption in Sweden currently is provided by nicotine medications and this level of medicinal nicotine intake greatly exceeds that of any other nation. Although overall intake of medicinal nicotine remains relatively low, relative to that from tobacco products its use is somewhat more frequent among females who account for approximately $60 \%$ of nicotine medication sales.

With respect to tobacco product marketing, differences between Sweden and most other countries have been equally profound. For decades there have been two major forms of tobacco consumption in Sweden, cigarettes and snus, although cigarette consumption has been predominant since approximately 1950 . Furthermore, the market for both tobacco product categories has been dominated by a single domestic company, Swedish Match. Because this company has made and marketed both cigarettes and smokeless tobacco products there has been an apparent greater willingness to allow one market (snus) to expand by fostering a transfer of consumers from the cigarette market. In fact, Swedish Match sold its cigarette business to an Austrian tobacco company (Austria Tabak) in 2000 and purchased a major cigar company. ${ }^{24} 25$

Although determinants of the trends are not well understood, there have been several changes in the modality of nicotine consumption in Sweden in the past two decades which are shown in fig 1 . Specifically, total nicotine consumption in Sweden declined by nearly $20 \%$ even as smokeless tobacco and nicotine replacement product use has 


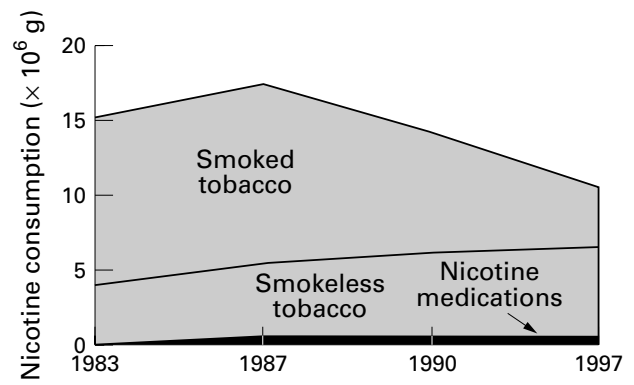

Figure 1 Total annual nicotine consumption in Sweden as delivered by smoked tobacco (primarily cigarettes), smokeless tobacco (snus), and nicotine medications (gum and patch). One cigarette and $1 \mathrm{~g}$ of snus has been estimated as $1 \mathrm{mg}$ of nicotine consumed. For nicotine replacement products only gums and patches have been accounted for since the sales of the others was negligible. Intake from patches was according to labelling, 21 or 15 $m g$, and 2 and $4 \mathrm{mg}$ gums were estimated to give 1 and 2 mg of nicotine.

increased. Of the current nicotine consumption, approximately $50 \%$ of nicotine consumption was provided by non-smoke sources (namely snus and nicotine medications) by the turn of the century. The main reduction in tobacco attributable mortality in Sweden is undoubtedly caused by the decline in cigarette smoking, and not by increased use of snus and nicotine medications per se, and the question remains as to the degree to which increased use of non-cigarette sources of nicotine have contributed to reduced smoking. A related question concerns the degree to which health policies can or should attempt to reduce tobacco attributable disease by increasing the use of other sources of nicotine. ${ }^{215}$

In consideration of health policies intended to transfer the source of nicotine among continuing nicotine dependent person from cigarettes to other sources it is important to consider the toxicity of the product. Cigarettes appear to be the most deadly of all tobacco products because of the toxicity of their smoke and because of the relatively deep and frequent exposure of the lung to their toxins that occur in most users compared to other forms of smoked and smokeless tobacco. ${ }^{242627}$ Nicotine medications are remarkably low in actual toxicity when compared to tobacco products and are regulated to minimise their toxicity. ${ }^{2}$ The primary health risk of smokeless tobacco is cancer of the mouth, nose, and throat, assumed to be primarily attributable to the tobacco specific nitrosamines, and there is an apparently small but real increased risk of heart disease that may be attributable to the high concentrations of nicotine delivered by such products. ${ }^{27-36}$ In the early 1980s, Swedish Match reduced the nitrosamine content of its snus products by adopting different processes for curing, manufacturing, storing, and handling of its products and this change may account for the apparently lower risk of head and neck cancers among Swedish snus users than among smokeless tobacco users in the USA. ${ }^{18}$ Of course such population comparisons must be treated with caution because confounding factors may be operative; nonetheless, the observations support the concept that reduction of tobacco product toxicity has potential to reduce product associated risk.

The foregoing should not be taken to imply that the health risks of smokeless tobacco use in Sweden are negligible. Furthermore, smokeless tobacco is addictive and frequently leads to chronic use, ${ }^{27}{ }^{29}$ which in turn leads to diseases of the gums and teeth which are not life threatening but can be debilitating and costly. ${ }^{27}{ }^{29}$ Finally, an additional risk that is evident in the USA is the greatly increased probability that young persons who use smokeless tobacco eventually switch to cigarettes and are more likely to abuse alcohol and other psychoactive drugs than non-smokeless users. ${ }^{12} 1337$

\section{Conceptual demonstration and limitations}

What can we learn from the Swedish experience? With care given to the limits of interpretation of the available data, the following lessons are noteworthy. Firstly, reductions in smoking are possible in an environment that includes a range of accessible nicotine delivering alternatives to cigarettes. Secondly, we believe it is probable that for persons who sustain their nicotine intake, education about the dangers of smoking and the marketing of alternative products can contribute to shifts in the nature of nicotine product use. ${ }^{223}$ This conclusion is also supported by the dramatic shift from the use of non-filtered to filtered cigarettes in the mid 20th century. ${ }^{26}$ Thirdly, reduced tobacco toxin exposure can lead to reduced premature mortality and this is not necessarily undermined by increasing prevalence of use of non-cigarette sources of nicotine. These effects and public health benefits have been predicted and discussed elsewhere. $^{5} 1738$

Several cautions and limitations must also be kept in mind, however. Firstly, Swedish snus contains ingredients that are more toxic than would be permitted in foods or medicines, and there are adverse health consequences, including oral diseases and addiction, although the adverse consequences are less severe than those produced by cigarette smoking. Secondly, whatever benefit of the substitution of smokeless tobacco for cigarettes in Sweden, the direct benefits have been limited to the male population because few females use smokeless tobacco; we do not suggest creating a new public health problem by attempting to stimulate use of smokeless tobacco by females in Sweden. Thirdly, it is not clear what the lifetime risk is of Swedish adolescent males transferring their smokeless tobacco use to smoked forms such as cigarettes, cigars, and pipes, all of which can be highly damaging. ${ }^{39}$

Fourthly, although it is possible that substitution of smokeless tobacco for cigarettes may have contributed to reducing smoking prevalence in Sweden from more than $30 \%$ to approximately $20 \%$, it is not yet clear if Sweden will continue its decline in smoking or will remain at present levels. It is noteworthy that in California and Massachusetts discouragement of all forms of tobacco use has resulted in lower 
prevalence of cigarette smoking and smokeless tobacco than in Sweden. ${ }^{40-42}$

\section{Conclusions}

The Swedish experience provides a useful conceptual demonstration of the potential benefits of a harm reduction approach that is integrated as part of an overall approach to prevent tobacco use and offer greater access to treatment for dependence. Tobacco attributable mortality in Sweden has declined following the declines of smoking prevalence. The decline in smoking appears to be primarily attributable to increased education about the dangers of tobacco use and the increased availability of treatments for tobacco dependence that have stimulated and supported cessation activity. Cessation is known to reduce disease risks. ${ }^{43}$

Comprehensive approaches such as are under consideration by the World Health Organization's Tobacco Control Framework Convention process, ${ }^{44}$ may benefit from evaluation of the Swedish experience because such efforts are intended to reduce tobacco attributed death and disease by more effectively preventing the initiation of use, stimulating and supporting cessation efforts, and reducing the toxicity of the products that are used. This should not be taken to imply that all aspects of the Swedish experience should be promoted or replicated. In particular, we have serious reservations about the promotion or seeming endorsement of any kind of tobacco product by the health community, particularly when pharmaceutical products developed specifically for the treatment of tobacco dependence are becoming increasingly available. We also believe that public health policy developers should be mindful of the complications of approaches that appear to promote any form of tobacco product use because such strategies could undermine prevention and cessation effort just as apparently did the promotion of light cigarettes. $^{289}$ We further concur with the US Institute of Medicine report conclusion that such tobacco toxin reduction approaches should be promoted only as part of comprehensive strategies to also promote cessation and prevention of tobacco use. ${ }^{2}$

Even as we learn from the developments in Sweden we need to monitor further developments because the experiment remains one in progress. The recent acquisition of a major cigar company by Swedish Match, ${ }^{24}{ }^{25}$ and its expressed intent to develop and market nicotine gum products and new smokeless tobacco products not for smoking cessation but for those not interested in giving up smoking for reduced smoking and in situations where they cannot smoke, ${ }^{45}{ }^{46}$ are tangible signs that the Swedish "experiment" remains in progress. Swedish Match is a publicly held company that has stated that its business developments are intended to provide more shareholder value. ${ }^{24} 25$ This implies that in the long run, it will need to expand its total business by creating new users for its products.
It is sobering that in the USA, efforts of smokeless tobacco companies to grow their business have resulted in substantial increases in smokeless tobacco use among young people and that overall smokeless tobacco consumption increased in the 1970s and 1980s followed by increased cigarette smoking in young people in the 1990s. ${ }^{21}{ }^{47}$ Yet another source of caution is that it is even less clear whether any sort of effort to steer a population to smokeless tobacco forms as opposed to cigarettes could or should occur in developing countries in which smokeless forms are already dominant, particularly in light of the probably even greater difficulty of controlling the toxicity of the smokeless products. ${ }^{48}$ The issues are extraordinarily complex and many of the important factors are outside the practical control of the health community, such as the nature of the competing commercial interests and the population preferences for nicotine intake form. ${ }^{49}$

As this commentary suggests, many factors determine the overall pattern of nicotine use and resultant health effects. We believe it is interesting and potentially useful to consider how these various forces contribute to differing patterns of product use in Sweden and the USA. As we noted earlier, the present assessment is not a recommendation of the Swedish approach for other countries to attempt to adopt. Nonetheless, we believe that consideration of the impact of the many forces at work in real world "experiments" such as Sweden can be useful as regulatory experts consider policies aimed at reducing the prevalence of tobacco use and tobacco caused death and disease. The experience in Sweden continues to evolve and it will be important to monitor the impact of the activities of Swedish Match, as it attempts to expand its nicotine market, on patterns of nicotine product use and public health.

\section{Addendum}

In the spring and summer of 2001, Swedish Match of North America, Inc, began test marketing Exhalt, in convenience stores throughout Ohio and North Carolina. The packages include "FOR SMOKERS" on their logo. The web site (myexhalt.com) provides coupons for free samples and discounts, as well as encouragement to use when smoking is not permitted or not convenient such as in the smoke free workplace, during movies, at home, and while swimming, noting "Exhalt is so discrete, nobody will know it's in but you-and there's no spitting".

JACK E HENNINGFIELD

Department of Psychiatry and Behavioral Sciences,

The fohns Hopkins University School of Medicine,

Baltimore, Maryland,

Research and Health Policy,

Pinney Associates,

Bethesda, Maryland, USA

Smokers Information Center,

KARL O FAGERSTROM

Fagerstrom Consulting,

Helsingborg, Sweden

The efforts of JEH were partially supported by an Innovators Combating Substance Abuse Award from the Robert Wood 
Johnson Foundation. The authors provide consultative services for GlaxoSmithKline Consumer Health Care which markets nicotine delivering medications for smoking cessation, and JEH has a financial interest in a nicotine gum product that is under development. Both authors have also provide consulting
services to other smoking cessation product marketers and KOF is a former employee of Pharmacia and Upjohn which markets smoking cessation products.

1 US Department of Health, Education, and Welfare. Smoking and health: report of the advisory committee to the Surgeon General of the Public Health Service, 1964. Washington, DC: Public Health Service 1964 (PHS Publication No 1103 .)

2 Stratton K, Shetty P, Wallace R, Bondurant S, eds. Clearing the smoke: assessing the science base for tobacco harm reduction. Institute of Medicine, National Academy of Sciences. Washington, DC: National Academy Press, 2001.

3 US Department of Health and Human Services. The FTC cigarette test method for determining tar, nicotine, and carbon monoxide yields of US cigarettes. Report of the National Cancer Institue Ad Hoc Committee. Rockville, Maryland: US Department of Health and Human Services; 1996. (NIH Publication No. 97-4213.)

4 Royal College of Physicians. Nicotine addiction in Britain: report of the tobacco advisory group of the Royal College of report of the tobacco advisory group of the Royal College

5 Slade R, Bickel WK, Crowley TJ, et al. The role of managing nicotine in controlling the tobacco epidemic. In Ferrence R, Slade J, Room R, Pope M, eds.. Nicotine and public health. Washington DC: American Public Health Association, 2000:483-501.

6 Slade J, Henningfield JE. Tobacco product regulation: context and issues. Food and Drug Law fournal 1998; 53(suppl):44-74

7 Bates C, McNeill A, Jarvis M, et al. The future of tobacco product regulation and labeling in Europe: implications for the forthcoming European Union directive. Tobacco Control 1999;8:225-35.

8 Gray N. Reflections on the saga of tar content: why did we

9 Leavell NR. The low tar lie. Tobacco Control 1999;8:433-9. amet JM. The changing cigarette and disease risk: current status of the evidence. In: NCI Monograph No 7. The FTC
cigarette test method for determining tar, nicotine, and carbon cigarette test method for determining tar, nicotine, and carbon
monoxide yields of US cigarettes. Report of the NCI Expert monoxide yields of US cigarettes. Report of the NCI Expert
Committee. Bethesda, Maryland: US Department of Committee. Bethesda, Maryland: US Department of Health and Human Services, Pub
National Institutes of Health, 1996.

11 Wilkenfeld J, Henningfield J, Slade D, et al. It's time for a change: cigarette smokers deserve about their cigarettes. F Natl Cancer Inst 2000:92:90-2.

12 US Department of Health and Human Services. Preventing tobacco use among young people. A report of the Surgeon General, 1994. Atlanta, Georgia: Public Health Service, Centers for Disease Control and Prevention, Office on Smoking and Health, 1994. (US Government Printing Office Publication No S/N 017-001-00491-0.)

13 Institute of Medicine. Growing up tobacco free: preventing nicotine addiction in children and youths. Lynch BS, Bonnie RJ, eds. Washington DC: National Academy Press, 1994.

14 Henningfield, JE, Radzius A, Cone EJ. Estimation of available nicotine content of six smokeless tobacco available nicotine content of six sm

15 Connolly GN. The marketing of nicotine addiction by one oral snuff manufacturer. Tobacco Control 1995;4:73-9.

16 Warner KE, Peck CC, Woosley RL, et al. Treatment of tobacco dependence: innovative regulatory approaches to reduce death and disease: Food and Drug Law fournal 1998;53(suppl.): $1-8$

17 Sweanor D. Regulatory imbalance between medicinal and non-medicinal nicotine. Addiction 2000;95(suppl):S25-8.

18 Ramstrom LM. Snuff-an alternative nicotine delivery system. In: Ferrence R, Slade J, Room R, Pope M, eds. Nicotine and public health. Washington DC: American Public Health Association, 2000:159-78.

19 Peto R, Lopez AD, Boreham J, et al. Mortality from smoking in developed countries 1950-2000. Oxford: Oxford University Press; 1994.

20 Koop CE. Don't forget the smokers. The Washington Post, 8 March 1998;C7.

21 Kessler DA, Witt AM, Barnett PS, et al. The Food and Drug Administration's regulation of tobacco products. $N$ Engl $\mathcal{F}$ 35:988-94

22 Henningfield JE, Fant RV, Shiffman S, et al. Tobacco dependence: scientific and public health basis of treatment. The Economics of Neuroscience 2000;2:42-6.
23 Shiffman S, Gitchell J, Pinney JM, et al. Public health benefit of over-the-counter nicotine medications. Tobacco Conefit of over-the-counte

24 Reuters. Swedish Match buys majority stake in General Cigar. Yahoo! Finance; 20 January 2000.

5 Reuters. FOCUS-Swedish Match takes major cigar stake in US. Yahoo! Finance; 20 January 2000.

26 Hoffman D, Hoffman I. The changing cigarette, 19501995. F Toxicol Environ Health 1997;50:307-64.

27 Connolly GN, Winn DM, Hecht SS, et al. The reemergence of smokeless tobacco. N Engl F Med 1986;314:1020-7.

28 Tomar SL, Henningfield JE. Additional evidence implicating moist snuff as

29 US Department of Health and Human Services. The health consequences of using smokeless tobacco: a report of the consequences of using smokeless tobacco: a report of the Maryland: National Institutes of Health: DHHS Publication No. (NIH) 86-2874, 1986.

30 Lewin F, Norell SE, Johansson H, et al. Smoking tobacco, oral snuff, and alcohol in the etiology of squamous cell carcinoma of the head and neck: a population-based casereferent study in Sweden. Cancer 1998;82:1367-75.

31 Schildt EB, Eriksson M, Hardell L, et al. Oral snuff, smoking habits and alcohol consumption in relation to oral cancer in a Swedish case-control study. Int $\mathcal{f}$ Cancer 1998; 77:341-6.

32 Lagergren J, Bergstrom R, Lindren A, et al. The role of tobacco, snuff, and alcohol use in the aetiology of cancer of the oesophagus and gastric cardia. Int $\mathcal{F}$ Cancer 2000; 85:340-6.

33 Ye W, Ekstrom AM, Hansson LE, et al. Tobacco, alcohol and the risk of gastric cancer by sub-site and histologic type. Int 7 Cancer 1999;83:223-9.

34 Huhtasaari F, Asplund K, Lundberg V, et al. Tobacco and myocardial infarction: is snuff less dangerous than cigarettes? $B M Y$ 1992;305:1252-6.

35 Huhtasaari F, Lundberg V, Eliasson M, et al. Smokeless tobacco as a possible risk factor for myocardial infarction: a population-based study in middle-aged men. $7 \mathrm{Am}$ Coll Cardiol 1999;34:1784-90.

36 Bolinder G, Alfredsson L, Englund A, et al. Smokeless tobacco use and increased cardiovascular mortality among Swedish construction workers. Am f Public Health 1994;83:399-404.

37 Henningfield JE, Clayton R, Pollin W. The involvement of tobacco in alcoholism and illicit drug use. $\mathrm{Br} \mathcal{F}$ Addiction 1990;85:279-92.

38 Warner KE, Slade J, Sweanor DT. The emerging market for long-term nicotine maintenance. $7 A M A \quad 1997 ; 278: 1087-$

39 Wald NJ, Watt HC. Prospective study of effect of switching from cigarettes to pipes or cigars on mortality from three moking related diseeses. $B M / \mathcal{1} 1997 \cdot 314: 1860-3$

40 Pierce JP, Gilpin EA, Emery SL, et al. Has the California tobacco control program reduced smoking? $\mathscr{F} A M A$ 1998;280:893-9.

41 Harris J, Connolly G, Davis B. Cigarette smoking before and after excise tax increase and anti-smoking campaign in Rep 1996;45:966-70.

42 Henningfield JE. Tobacco dependence treatment: scientific challenges; public health opportunities. Tobacco Control 2000;9(suppl I):i3-10

43 US Department of Health and Human Services. The health benefits of smoking cessation. A report of the Surgeon General, 1990. Rockville, Maryland: Public Health Service, Centers for Disease Control, Office on Smoking and Health, 1990. (DHHS Publication No (CDC) 90-8416.)

44 Joossens L. Improving public health through an international framework convention for tobacco control. World Health Organization Technical Document WHO/NCD/TFI/ 099.2, April 1999

45 Wheeler B. Nicotine gum bites off more than it can chew. Marketing Week, 6 July 2000;20.

66 Swedish Match. Swedish Match announces test market of ExaltTM - an alternative for smokers. Business Wire, 27 April 2001.

47 Centers for Disease Control and Prevention. Tobacco use among high school students-United States, 1997. MMWR Morb Mortal Wkly Rep 1998;47:229-33.

48 Asma S. Smokeless tobacco: betel quid chewing among adult women in Lao People's Democratic Republic. Tobacco Control 1997;6:157-8.

49 Ferrence R, Slade J, Room R, Pope M, eds. Nicotine and public health. Washington DC: American Public Health Association, 2000 